\title{
VIOLENCIA INTRAFAMILIAR: LA REPARACIÓN INTEGRAL COMO UN DERECHO EN EL ECUADOR ${ }^{\mathrm{I}}$ \\ Domestic Violence: Comprehensive Reparation as a Right in Ecuador
}

\author{
Mercedes Angélica Ortega Pérez ${ }^{2}$ \\ Universidad Cesar Vallejo, Trujillo, Perú \\ Cruz Xiomara Peraza de Aparicio 3 \\ Universidad Metropolitana, Guayaquil, Ecuador
}

\section{Resumen}

La violencia es un problema que viene afectando a las distintas esferas de la sociedad. El tema debe ser tratado con responsabilidad e interés por parte de cada una de las partes integrantes de la sociedad. El objetivo del artículo es analizar la violencia intrafamiliar que sufre la mujer en el hogar y cómo se da la Reparación Integral como un derecho en el Ecuador. Se realizó una investigación documental basada en una revisión bibliográfica de revistas relacionadas con el área asentada en bases de datos especializadas. Como resultados se evidencia que existe la Reparación Integral como un derecho constitucional en el Ecuador. La importancia de la Reparación radica en el hecho de lograr que la víctima regrese a la situación antes de los eventos de violencia, y que la mujer se empodere de su rol. Como conclusión se establece que los efectos de la violencia intrafamiliar deben de ser identificados como agentes detonantes a la alteración del núcleo familiar que se refleja en: maltrato físico, cambios comportamentales, lesiones psicológicas que ocasionan baja autoestima, depresión, e incluso pudiendo llegar a la muerte. Por tal razón, la Reparación Integral es un derecho irrenunciable de las víctimas.

\section{Palabras clave}

Violencia intrafamiliar, familia, reparación integral, víctima, derechos humanos, mujeres.

\begin{abstract}
Violence is a problem that has been affecting the different spheres of society. The issue must be treated with responsibility and interest by each of the integral parts of society. Therefore, the objective of this article is to analyze domestic violence suffered by women in the home and how Comprehensive Reparation is provided as a right in Ecuador. A documentary research was conducted, based on a bibliographic review of journals related to the area settled in specialized databases. The results show that Integral Reparation exists as a constitutional right in Ecuador. The importance of reparation lies in the fact that the victim returns to the situation before the events of violence, and that the woman is empowered in her role. In conclusion, it is established that the effects of domestic violence should be identified as triggering agents for the alteration of the family nucleus, which is reflected in: physical abuse, behavioral

\footnotetext{
${ }^{1}$ Las autoras de este artículo han contribuido en partes iguales.

${ }^{2}$ Abogado, Master en Derecho Constitucional. Correo electrónico: ab.mercedesortega@gmail.com; ORCID: https://orcid. org/0000-0003-3633-8575.

${ }^{3}$ Médico Cirujano, Master en Planificación Educativa, Doctora en Ciencias de la Educación. Correo electrónico: cperaza@ umet.edu.ec; ORCID: https://orcid.org/0000-0003-2588-970X.
} 
changes, psychological injuries that cause low self-esteem, depression, and may even lead to death. For this reason, Integral Reparation is an inalienable right of the victims.

\section{Keywords}

Domestic violence, Family, Comprehensive Reparation, Victim, Human Rights, Women.

\section{Introducción}

Desde tiempos inmemoriales, la familia ha sido considerada como la célula básica de la sociedad, reconociendo que su naturaleza, funciones y aportes son fundamentales para el desarrollo económico y social de las naciones. También es cierto que a lo largo de la historia se ha visto el machismo imperante en la sociedad; el patriarcado, en el que la mujer se ha visto inmersa en situaciones de vulnerabilidad al ser maltratada no sólo por su pareja, esposo o conviviente, sino también por la figura paterna. El tema de la violencia contra la mujer y contra los miembros del núcleo familiar ha generado un sin número de debates en el ámbito social y legal a nivel mundial, la conceptualización, el contenido y alcance del mismo ha dado paso a amplias opiniones en su dinámica teórica y sigue transformándose hasta el día de hoy.

En todos los lugares del mundo y desde siempre, refiere Gil (2019), se viene ejerciendo una violencia sistemática sobre la mitad de la población, las mujeres. Desde hace unas décadas esa mitad de la población ha optado por unir esfuerzos y visibilizar esa violencia social, cultural, física y estructural que su colectivo sufre, con el objetivo de comprender, analizar y encontrar soluciones al origen de esa opresión.

En opinión de Bofarull (2005), familias fuertes, saludables y sostenibles, derivan en sociedades fuertes y saludables. Por el contrario, un debilitamiento de las estructuras y dinámicas familiares impacta desfavorablemente en la sociedad, al provocar problemáticas que afectan los indicadores de bienestar en los miembros de los hogares, especialmente de los menores de edad.

Cuando los indicadores de bienestar se deterioran a nivel familiar, se aprecia desatención en el cuidado de los niños, abandono escolar, aumento de adicciones, violencia intrafamiliar, entre otros. El Estado debe responder con programas y proyectos que mitiguen las diversas problemáticas, las cuales pudieron evitarse o reducirse con una atención y protección oportuna a las familias especialmente vulnerables (Pliego, 2014).

Sin embargo, según Madrid y Reyes (2019), los cambios culturales han actuado también como factores desafiantes en la vida familiar. Las familias tenían mayor estabilidad, por su apego hacia una cultura comunitaria fiel a las tradiciones. Hoy en día las relaciones entre las generaciones dentro de la familia se están volviendo más inciertas y confusas. Los padres están enfrentando problemas con respecto a cómo mantener su autoridad en una sociedad y una cultura que da más espacio a los niños y jóvenes. Mientras el discurso social reproduce la idea y el miedo sobre el ocaso de la familia, en las encuestas de opinión y en las de investigación aparece una y otra vez el deseo de los jóvenes de formar sus propias familias y el de los adultos de mantenerse viviendo en familia.

Los estudios como los de Oudhof et al (2018), revelan las convergencias y divergencias en las trayectorias de los integrantes de la familia, las mutaciones y permanencias en las prácticas de crianza y las nuevas alternativas que emergen, bien como iniciativa individual y particularizada, o como respuesta/resistencia que han tenido las familias a dichos cambios.

En décadas recientes según Oudhof, se han producido cambios significativos en su estructura, su tamaño, las relaciones entre sus integrantes y sus vínculos con otras insti- 
tuciones y grupos. Una de las transformaciones más marcadas es la creciente pluralidad de tipos de familia y la variedad cada vez más evidente de sus formas de organización, lo cual tiene como consecuencia que el mismo concepto de familia se haya vuelto cada vez más complejo. Esta diversificación ha intensificado el debate y la polémica acerca de lo que es y lo que debe ser la familia, así como sobre los procesos psicológicos y sociales que se desarrollan en el ámbito familiar, entre los que destaca la crianza de los hijos.

La tasa de natalidad explica Cabella \& Natan (2018), se ha reducido significativamente en muchos países, incluso llegando a niveles por debajo de la tasa de reemplazo generacional ( 2 hijos por mujer). La población adulta mayor ha crecido, pero las generaciones jóvenes y las personas en edad productiva tienden, en los próximos ańos, a disminuir. Por su parte, los hogares monoparentales, principalmente dirigidos por mujeres, han aumentado, elevando igualmente los problemas de pobreza asociados con esta realidad.

Tal situación contribuye a que la mujer sea víctima de violencia, afectaciones no solo de orden físico sino además de orden psicológico, trastocando todo el entorno familiar, convirtiéndolo en un círculo vicioso del que es muy difícil que salga y despierte para romper las barreras y denunciar. Quienes se atreven lo hacen con miedos internos, afectaciones psicológicas que marcan su vida.

En Latinoamérica, Illescas et al (2018), comentan que en un estudio realizado en Ecuador sobre la violencia de género establece que 6 de cada10 mujeres han sido víctimas de algún tipo de violencia. Existen diferentes factores que ubican a ciertas mujeres en mayor condición de vulnerabilidad como aquellas que tienen algún tipo de discapacidad, por ser indígenas, o aquellas que son miembros de hogares con bajos recursos económicos. De la misma manera, expresan que aquellas mujeres que tienen un nivel alto de educación son menos propensas a sufrir este tipo de maltratos, sin embargo, no excluye de que alguna vez puedan ser sometidas a los mismos. Lo cual deja ver que el machismo y la violencia a la mujer se encuentran arraigados en la sociedad. A manera de ejemplificar, se cree que la mujer solo sirve para criar hijos y quehaceres del hogar, no obstante, esto degrada su función en la sociedad, colocándola en una situación de vulnerabilidad. Es así como a nivel nacional como internacional se visualiza la lucha tanto de mujeres como de organizaciones para erradicar este mal.

En cuanto a las implicaciones legales, el Código Civil dice que el que ha cometido un delito o cuasidelito que ha dańado a otro está obligado a la indemnización, sin perjuicio de la pena que le impongan las leyes por ese delito o cuasidelito. Si las leyes no han aplicado expresamente una pena, el autor del hecho solo tendrá la obligación civil de indemnizar el daño que con su acto ilícito ha causado, por ende, no habrá delito, penalmente hablando, aunque haya delito civil. Como consecuencia del delito la responsabilidad civil se erige para ser satisfecha en tres elementos a saber: 1) la restitución, 2) la reparación del daño causado y, 3) la indemnización de perjuicios. La restitución debe hacerse de la misma cosa, con abono de deterioros. La reparación consiste en la valoración del daño, por parte del tribunal, tomando en cuenta el precio del bien y la afección del agraviado, lo cual da paso al resarcimiento del daño moral. La indemnización de perjuicios materiales y morales comprende los causados a la víctima y los irrogados a su familia o a terceros por el delito.

Por otra parte, y en concordancia con el artículo 70 de la Constitución de la República del Ecuador, orienta su desarrollo formal y material hacia el efectivo goce de derechos para alcanzar la igualdad entre mujeres y hombres, mediante la Política de Igualdad de Género (2018).

En esta línea, el Estado ecuatoriano ha implementado progresiva y sistemáticamente en su ordenamiento legal y en sus políticas públicas, los compromisos en materia de derechos 
humanos que se derivan de la ratificación de la Convención sobre la Eliminación de Todas las Formas de Discriminación Contra la Mujer (CEDAW, por sus siglas en inglés); y, de la Convención Interamericana para Prevenir, Sancionar y Erradicar la Violencia Contra la Mujer (Convención Belem do Pará). Así mismo, el Gobierno se ha comprometido a implementar la Agenda 2030 y los Objetivos de Desarrollo Sostenible. La igualdad de género es un elemento central de dicha agenda, cuyo Objetivo 5 se refiere específicamente a la igualdad de género y al empoderamiento de las mujeres, nińas y adolescentes. Por todo lo antes expuesto, el objetivo de este artículo es analizar la violencia intrafamiliar y la Reparación Integral como instrumento legal y un derecho en Ecuador. En el desarrollo del mismo se revisa brevemente tópicos como la familia desde la óptica transdisciplinaria, la violencia familiar: causas y consecuencias; la Reparación Integral desde lo constitucional, conclusiones y referencias.

\section{Desarrollo}

\subsection{La familia desde la óptica transdisciplinaria}

La visión de la familia desde el enfoque de lo complejo invita a reflexionar sobre sus relaciones con el sistema social, esto permite la integración de un cúmulo de resultados y conocimientos que se han ido obteniendo en las diferentes ciencias (Naturales, Biológicas y Sociales) para integrar un cuerpo de conocimientos que ha posibilitado el enfoque transdisciplinario a fenómenos y procesos de la realidad. La complejidad emergente de la realidad, con sus crecientes flujos de información, ha generado la necesidad de un nuevo modo de pensar y observar los procesos.

De ahí que los cambios producidos en la familia deban ser analizados a la luz de los cambios sociales que se han producido en los últimos años y que han impactado la dinámica de diferentes instituciones y grupos de la sociedad. En "El carácter histórico de la familia y las transformaciones sociales contemporáneas” señala que:

[...] en la perspectiva de esta realidad dual de la familia, las transformaciones en las relaciones sociales, económicas y políticas contemporáneas la afectan de una manera compleja: no en forma de una determinación directa, sino en forma de oposiciones entre su comportamiento concreto y el comportamiento esperado [...] (Reuben, 2003).

Con los aportes de Morgan (1971), el resultado del análisis de los sistemas de parentesco orientó a la Antropología hacia el estudio de este tema, pues descubrió la importancia que las diferentes terminologías tienen para los sistemas culturales, pues sirven para organizar, clasificar y discriminar a los diferentes individuos y grupos, así como las relaciones que entre ellos se establecen.

El carácter institucional de la familia conlleva a que la misma tenga una relación constante y un nexo muy fuerte con la sociedad, "[...] no solo por constituir el mejor espacio de vínculo e interacción entre el individuo y el sistema social, sino como espacio privilegiado para la acción de políticas sociales y económicas" (Díaz, et al, 2004). Como institución no solo define quienes, sino que tipo de necesidades deben atender los individuos que la integran, y se manifiesta como un componente del sistema social, que interactúa con disímiles instituciones sociales públicas y privadas.

Desde la visión de la sociología, Ariadna (2021) refiere que, por el tipo de organización, la familia puede ser: Patriarcal: la autoridad la ejerce el padre; Matriarcal: la autoridad la ejerce la madre; Igualitaria: la autoridad esta compartida entre padre y madre; Patrilineal: solo a los miembros varones de la familia se les puede heredar; Matrilineal: solo a los miembros femeninos de la familia se les puede heredar; Bilineal: todos los miembros 
de la familia se les puede transmitir la pertenencia; y, Soporte: cuando los padres por sus responsabilidades laborales y extensas jornadas no cuentan con tiempo suficiente para dedicarlo a los hijos, delegan parte de sus obligaciones a los hijos mayores para el cuidado de sus hermanos más pequeños.

Dentro de los distintos tipos de familia hay conflictos que les atañen y que de manera directa o indirecta afectan a la propia sociedad. De los que se pueden ejemplificar se encuentran: 1) desacuerdos de pareja por problemas financieros; 2) falta de entendimiento por diferencia de caracteres; 3) pérdida del trabajo; 4) enfermedad incapacitante; 5) adicciones, 6) infidelidad; 7) mala relación con los padres de la pareja; 8) extensas jornadas laborales que limita la convivencia; 9) comportamiento violento; 10) peleas entre los miembros de la familia (por la diferencia generacional entre padres e hijos); 11) dificultad para lograr una crianza acorde a las necesidades de los hijos y al mismo tiempo su manutención, entre otros (Ariadna, 2021).

\subsection{La violencia familiar: causas y consecuencias}

La violencia intrafamiliar o violencia doméstica, refiere Canseco et al, a toda acción u omisión cometida por algún integrante familiar en relación de poder, sin importar el espacio físico donde ocurra. En estos últimos ańos se han venido dando una serie de programas y leyes en defensa de los derechos de los miembros de la familia. Sin embargo, esto no asegura el bienestar del hogar, por ser un problema social de grandes dimensiones que afecta sistemáticamente a importantes sectores de la población, especialmente a mujeres, niñas, nińos, adolescentes, ancianos y ancianas.

La violencia, en la mayoría de los casos, ha llegado a ser parte de la vida cotidiana de muchas personas a las cuales afecta en gran manera su comportamiento y el desarrollo de diversas actividades que deseen ejercer; es decir, la violencia también es una conducta aprendida. La violencia puede manifestarse en cualquier ámbito social como el cultural, político, económico y el ámbito social doméstico (Canseco et al, 2019).

En cuanto a los factores que aparecen como generadores de violencia intrafamiliar, según Torres (2018), existen frases que se han normalizado en la sociedad y que agraven la problemática, por ejemplo: 1) "Los hombres son fuertes y las mujeres débiles", 2) "los hombres no lloran", 3) "El hombre es proveedor y la mujer es dependiente", etc. En la sociedad, la cultura transmite ideales de violencia de género contra las mujeres y se la ha justificado a través del tiempo por 'cuestiones' culturales. En otras palabras, no es algo natural sino una tendencia aprendida y, por lo tanto, es susceptible de cambio.

Entre las consecuencias de la violencia intrafamiliar, comenta Torres que se produce un sinnúmero de efectos adversos para las víctimas y para la sociedad, señalando así: 1) deterioro de su salud física, pudiendo llegar a ser víctimas de femicidio; 2) mayor riesgo de padecer trastornos psicológicos, como estrés postraumático, depresión, baja autoestima, incluso cometer suicidio; 3) exposición a una serie de problemas de salud sexual y reproductiva, como contraer VIH-SIDA e infecciones de transmisión sexual, y; 4) dificultades para trabajar, e incapacidad de participar o ser autónomas económicamente. La violencia acarrea altísimos costos económicos y sociales para el Estado, y constituye una fuerte carga para el sistema público ecuatoriano, pues implica el costo de la atención en salud y los servicios de atención a víctimas.

La violencia intrafamiliar parte de la falta de comunicación en el hogar, lo que conlleva a la inexistencia de un diálogo afable que permita expresarse de manera libre y voluntaria. Si esto sucediera se evitaría escenas de violencia que en algunos casos terminan con la muerte de uno de los cónyuges. 
Los ataques físicos y emocionales, comenta Gorski (2017), forman parte de la violencia crónica. Es importante detectar a tiempo una "relación tóxica" para de esta manera, ayudar a las mujeres que podrían ser futuras víctimas.

De igual manera Bentivegna (2016), explica cómo se desarrolla el "ciclo de la violencia”, el cual está constituido por tres etapas. Las interacciones violentas dentro de la pareja están vinculadas con un incremento de la tensión en las relaciones de poder establecidas.

\begin{tabular}{|c|c|c|}
\hline $\begin{array}{c}\text { Fase I: "De acumulación } \\
\text { de tensión" }\end{array}$ & Fase II: "Del Golpe" & $\begin{array}{c}\text { Fase III: "De idealización o luna de } \\
\text { miel" }\end{array}$ \\
\hline $\begin{array}{l}\text { - Pequeńos episodios roces } \\
\text { permanentes entre los miem- } \\
\text { bros de una pareja. } \\
\text { - Incremento constante de } \\
\text { ansiedad y de hostilidad. } \\
\text { - Esta fase puede durar años. } \\
\text { - Si la víctima busca ayuda se } \\
\text { puede prevenir la irrupción } \\
\text { de la fase aguda o del golpe. }\end{array}$ & $\begin{array}{l}\text { - La mujer, frente al } \\
\text { golpe, lleva a cabo la de- } \\
\text { nuncia judicial. } \\
\text { - Violencia física se con- } \\
\text { vierte en un detonador. }\end{array}$ & $\begin{array}{l}\text { - Arrepentimiento por parte del él. } \\
\text { - La mujer lo perdona y vuelve a creer en } \\
\text { su pareja debido a su escasa capacidad de } \\
\text { poner en palabras lo que siente y piensa. } \\
\text { - Él demuestra su arrepentimiento y suele } \\
\text { hacerle regalos para que ella vea que es el } \\
\text { hombre del cual se enamoró. } \\
\text { - Frente a tal comportamiento, la mujer } \\
\text { deja sin efecto la denuncia. }\end{array}$ \\
\hline
\end{tabular}

Figura 1. Ciclo de la violencia. Bentivegma (2017).

Es de suma importancia la detección de las señales de ayuda o indicios que el amigo o familiar de la víctima pueda detectar. La presencia de conductas como la separación de su círculo íntimo, dejar de trabajar, aislarse socialmente, volverse más tímida, negar o justificar la violencia son algunas de las actitudes que poco a poco formarán parte de la conducta y personalidad de la víctima.

En la realidad latinoamericana, Mayor \& Salazar (2019), sobre los aspectos legales en Colombia, establecen que hombres y mujeres tienen iguales derechos, recogidos en las leyes 599 y 600 del 2000 y en la 1542 del 2012 del Código Penal. En Bolivia se ha difundido la Ley 1674 contra la violencia en la familia, con el fin de brindar protección jurídica a los más vulnerables en el contexto del hogar. En Perú, actualmente uno de los países con altos índices de violencia contra las mujeres en el seno familiar, se crearon Centros de Emergencia Mujer (CEM) del Ministerio de la Mujer y Poblaciones Vulnerables (MIMP), con el objetivo de identificar y atender los casos de violencia sexual y homicidios ocurridos.

Por otra parte, en el Ecuador, a lo largo de los años el abuso y la violencia de género se ha transformado en una problemática social que alarma en su totalidad al país. Problema que, por regla general, se encuentra o se origina en la mayoría de los casos dentro del hogar, estableciendo un agresor y una víctima en un proceso sistemático que se manifiesta con la violencia psicológica, luego con la violencia física y sexual a través de maltratos y violaciones, y que terminan con la muerte de la víctima.

En el Ecuador, según la Fundación Aldea (2018), cada 3 días se reporta un nuevo caso de Femicidio. Así lo señalan los registros de cuatro organizaciones de la sociedad civil: Fundación Aldea, Red de Casas de Acogida, Taller Comunicación Mujer y la Comisión Ecuménica de los Derechos Humanos.

Para el año 2021, según Espinoza (2021) la situación se torna con una mayor magnitud, 105 feminicidios se registraron en todo el Ecuador solo en seis meses; es decir, una mujer es asesinada cada 41 horas. 


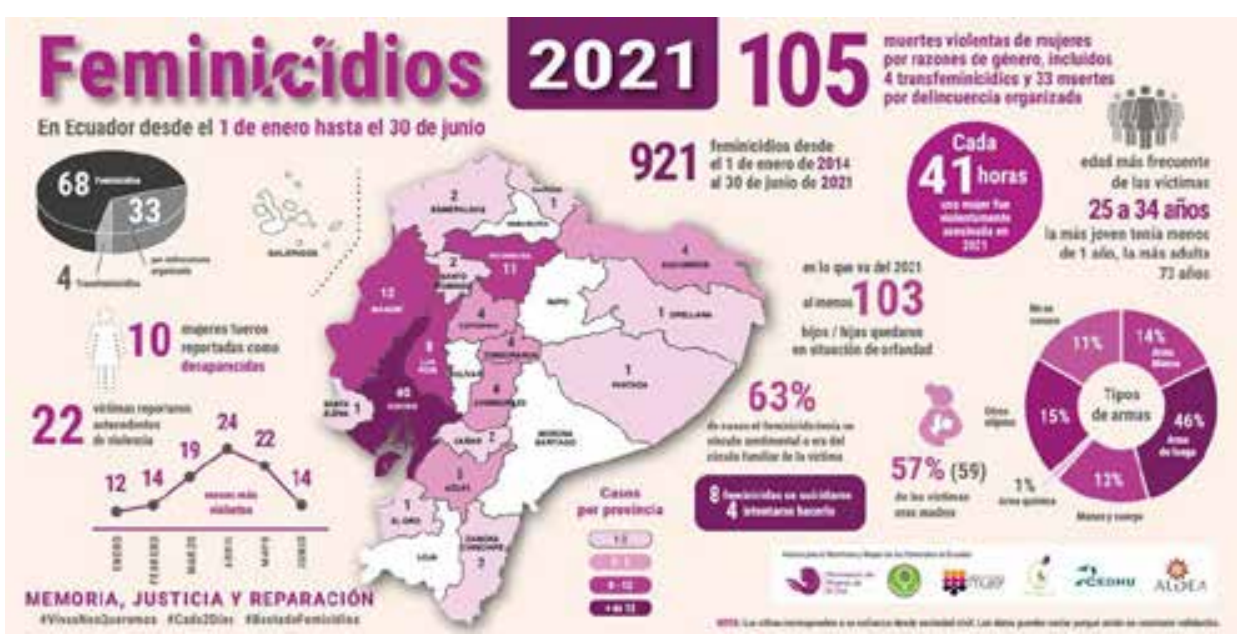

Figura 2. Femicidios en Ecuador desde el 1 de enero hasta el 30 de junio de 2021. Alianza para el monitoreo y Mapeo de Femicidios en el Ecuador (2021).

Los datos indican que el $63 \%$ de los casos, el feminicida tenía un vínculo sentimental o era del círculo familiar de la víctima. A causa de los 105 feminicidios registrados en lo que va de 2021, al menos 103 hijos e hijas quedaron en la orfandad.

Sobre la tipificación del femicidio explica Sacomano que, "[l]a tipificación del feminicidio crea una herramienta en contra del crimen y en contra de la impunidad, que implica mecanismos y políticas específicas para investigar, prevenir y combatir la violencia extrema por razón de género" (2017, p. 62). El femicidio, se tipificó a fin de individualizar y separar el homicidio y su relación con las mujeres, limitando el sujeto pasivo y activo en la tipificación del delito, a más de la tipificación en sí, se establecieron medidas correctivas de protección y prevención de la violencia contra la mujer, a fin de contrarrestar la materialidad del femicidio, brindándole ayuda al encontrarse en una situación de vulneración.

\subsection{La Reparación Integral desde lo Constitucional}

En la Constitución de 2008 se instauró un modelo constitucional enfocado al reconocimiento del goce y ejercicio pleno de los derechos constitucionales y los derechos humanos que se encuentran sustentados en tratados internacionales. Cualquier transgresión a estos derechos deberá ser reparada, en la medida que la persona afectada tenga la opción de retomar el ejercicio de los derechos que le han sido vulnerados, y correspondiendo al Estado canalizar el proceso dirigido al resarcimiento así como la vigilancia de su cumplimiento y ejecución. En este sentido, Abad (2020) comenta que, en caso que se evidencien violaciones a los derechos constitucionales, el Estado está obligado ineludiblemente a proceder a la reparación desde el punto de vista jurídico y social, como una forma de materializar la prevalencia de los derechos constitucionales. Entre los deberes que los Estados se han impuesto es impedir la ocurrencia de nuevas violaciones, asegurando "el derecho de las víctimas a interponer recursos y obtener reparaciones", a través del cual, "la comunidad internacional hace honor a su palabra respecto del sufrimiento de las víctimas, los supervivientes y las generaciones futuras y reafirma los principios jurídicos internacionales de responsabilidad, justicia y Estado de derecho”.

La reparación integral, implica que toda resolución o sentencia debe ir acompañada de este derecho, valorando la afectación que cause, además de indicar el tiempo que durará 
dicha medida, cómo se efectuará y el seguimiento que debe darse a la misma, ya que esta constituye no solo un derecho sino además una garantía para las víctimas de todo tipo de violencia. En el mismo orden de ideas, Escudero (2013), indica lo siguiente:

[...] la palabra reparación hace referencia a un amplio rango de medidas que pueden adoptarse a una violación real o potencial que abarca tanto la sustancia de la ayuda, así como el procedimiento a través del cual se la puede obtener. En esencia, no existen parámetros definidos para un único uso de la palabra, pero para efectos del reconocimiento de los Estados, se expresa como una doble obligación hacia las víctimas: para que sea posible el alivio del dańo sufrido y para proporcionar un resultado final que en realidad ocupa el daño. Para decirlo de otra manera, la justicia para las víctimas exige genuinos mecanismos procesales que resulten en el alivio final y positivo de la vulneración de derechos (sustancia de la reparación) (p. 275).

De igual manera, el Código Orgánico Integral Penal (COIP), publicado en el suplemento del registro oficial No. 180 en fecha 10 de febrero del año 2014, trajo consigo la Reparación Integral como una forma de resarcimiento a las víctimas, siendo una figura nueva en el ordenamiento jurídico interno del país.

El artículo 77 del COIP establece que "[1]a reparación integral radicará en la solución que objetiva y simbólicamente restituya, en la medida de lo posible, al estado anterior de la víctima, cesando los efectos de las infracciones perpetradas. Su naturaleza y monto dependen de las características del delito, bien jurídico afectado y el daño ocasionado". La restitución integral constituye un derecho y una garantía para interponer los recursos y las acciones dirigidas a recibir las restauraciones y compensaciones en proporción con el daño sufrido.

El artículo 78 del COIP establece los mecanismos de reparación integral literalmente: "Las formas no excluyentes de reparación integral, individual o colectiva, son: 1) La restitución: se aplica a casos relacionados con el restablecimiento de la libertad, de la vida familiar, de la ciudadanía o de la nacionalidad, el retorno al país de residencia anterior, la recuperación del empleo o de la propiedad, así como al restablecimiento de los derechos políticos; 2) La rehabilitación: se orienta a la recuperación de las personas mediante la atención médica y psicológica, así como a garantizar la prestación de servicios jurídicos y sociales necesarios para esos fines; 3) Las indemnizaciones de daños materiales e inmateriales: se refieren a la compensación por todo perjuicio que resulte como consecuencia de una infracción penal y que sea evaluable económicamente; 4) Las medidas de satisfacción o simbólicas: se refieren a la declaración de la decisión judicial de reparar la dignidad, la reputación, la disculpa y el reconocimiento público de los hechos y de las responsabilidades, las conmemoraciones y los homenajes a las víctimas, la enseñanza y la difusión de la verdad histórica; y, 5) Las garantías de no repetición: se orientan a la prevención de infracciones penales y a la creación de condiciones suficientes para evitar la repetición de las mismas.

Se identifican con la adopción de las medidas necesarias para evitar que las víctimas sean afectadas con la comisión de nuevos delitos del mismo género. Estas dos disposiciones, como se conocen, son las más recientes que se han incorporado sobre este tema en la legislación a consecuencia de la puesta en vigencia de este novísimo cuerpo normativo que ha merecido amplios comentarios tanto de sectores especializados, como no vinculados al quehacer jurídico diario.

Refiere Machado et al (2018), que con el contenido de las normas transcritas en el COIP, ahora sí, se ha establecido la reparación integral como un auténtico derecho de las 
víctimas y ha detallado con absoluta claridad los mecanismos con los cuales se puede cumplir aquella, haciendo hincapié en el hecho de que la elección de alguno de ellos no excluye la posibilidad de que pueda coexistir con otro u otros, que a criterio del juzgador deban decretarse para alcanzar la satisfacción de quién padeció el daño no estando obligado a hacerlo. La aplicación de estas disposiciones ha revolucionado todo lo referente a la reparación de los daños en materia penal, quizá este es uno de los aspectos más destacados y relevantes que todos han reconocido como una fortaleza del COIP.

El bien jurídico protegido en los casos de violencia intrafamiliar es la vida, ya que de ella emanan una serie de derechos que tienen las personas como lo es la dignidad, la libertad, el libre desarrollo de la personalidad, la igualdad, la no discriminación, la integridad personal. Por lo que tienen el derecho de una reparación integral, el mismo que además de encontrarse en la Constitución, se encuentra contemplado en los tratados internacionales como ya se ha mencionado en especial el de la Convención Belém Do Para (1995).

El artículo 18 de la Ley Orgánica de Garantías Jurisdiccionales, en relación con la reparación integral dice: "En caso de declararse la vulneración de derechos se ordenará la reparación integral por el daño material e inmaterial. La reparación integral procurará que la persona o personas titulares del derecho violado gocen y disfruten el derecho de la manera más adecuada posible y que se restablezca a la situación anterior a la violación. La reparación podrá incluir, entre otras formas, la restitución del derecho, la compensación económica o patrimonial, la rehabilitación, la satisfacción, las garantías de que el hecho no se repita, la obligación de remitir a la autoridad competente para investigar y sancionar, las medidas de reconocimiento, las disculpas públicas, la prestación de servicios públicos, y la atención de salud.

La reparación por el daño material comprenderá la compensación por la pérdida o detrimento de los ingresos de las personas afectadas, los gastos efectuados con motivo de los hechos y las consecuencias de carácter pecuniario que tengan un nexo causal con los hechos del caso. La reparación por el daño inmaterial comprenderá la compensación mediante el pago de una cantidad de dinero o la entrega de bienes o servicios apreciables en dinero, por los sufrimientos y las aflicciones causadas a la persona afectada directa y a sus allegados. Son además objeto de reparación, las alteraciones de carácter no pecuniario, en las condiciones de existencia del afectado o su familia. La reparación se realizará en función del tipo de violación, las circunstancias del caso, las consecuencias de los hechos y la afectación al proyecto de vida.

El fenómeno de la violencia intrafamiliar, en los últimos ańos ha merecido gran interes por parte del Estado, iniciando así diversos tipos de acciones de orden constitucional, convencional y legal; considerándolo además como un problema que afecta de manera directa a la sociedad por lo que se han creado diversos tipos de políticas públicas encaminadas a frenar los hechos y a proteger a la mujer y a la familia de la violencia intrafamiliar. Esto debido a los altos índices de denuncias tanto en los juzgados contravencionales de violencia contra la mujer y la familia, así como en las Fiscalías de Violencia de Género en el País. Con la reparación integral, Ecuador asumió así su compromiso y respeto a los derechos humanos, incluyendo este nuevo mecanismo de justicia en todo ámbito, incluso en el objeto de este análisis, como lo es la violencia intrafamiliar, se ha constituido como una garantía eficaz para el resarcimiento de los derechos vulnerados en especial de los derechos humanos.

En Ecuador, se necesita la profundización en el estudio del alcance de lo que significa la reparación integral, ya que no es únicamente la indemnización ni unas disculpas 
públicas, abarca más allá de eso, como lo es el daño que ha ocasionado, la vulneración de los derechos en las víctimas cuantificarlos de manera concienzuda, la garantía de no repetición, que esta sea justa y eficaz en este caso de estudio para las contravenciones de violencia intrafamiliar. Es decir, la reparación no se limita a dos cosas, por lo que se hace necesario determinar lo que es la reparación integral y su ámbito de aplicación.

La Corte Interamericana de Derechos Humanos, en la sentencia del caso peruano No. 144, caso Acevedo vs. otros de 2004, señaló lo siguiente: "Las reparaciones son medidas que tienden a hacer desaparecer los efectos de las violaciones cometidas. Su naturaleza y su monto dependen de las características de la violación y del daño ocasionado en los planos material e inmaterial [...]" (p. 95).

Para que este tema de la reparación no resulte una mera quimera jurídica, Cornejo (2016) explica que dicha reparación integral debe ser analizada por el juez para calcular los daños de una manera prudente acorde al mérito del proceso desde algunas visiones que consideren: 1) el Daño Emergente; 2) el Lucro Cesante, y; 3) el Dańo Moral. Adicionalmente, y a efectos de la adopción de medidas tendientes a efectivizar una reparación integral, las autoridades judiciales deben tener presente algunos elementos, tales como: 1) Restitución; 2) Restauración de la libertad, bienes o educación; 3) Compensación o indemnización por cualquier daño económicamente evaluable; 4) Rehabilitación: ayuda médica, psicológica, prestación de servicios legales y sociales, y; 5) Satisfacción: la aplicación de sanciones judiciales y garantías de no-repetición.

\section{Conclusiones}

Los cambios producidos en la familia deben ser analizados a la luz de los cambios sociales que se han producido en los últimos años, y que han impactado la dinámica de diferentes instituciones y grupos de la sociedad.

En Ecuador, el abuso y la violencia de género se ha transformado en una problemática social que alarma al país. Problema que por regla general, se encuentra o se origina en la mayoría de los casos dentro del hogar, estableciendo un agresor y una víctima, en un proceso sistemático que se manifiesta con la violencia psicológica, luego con la violencia física y sexual a través de maltratos y violaciones, y que terminan con la muerte de la víctima.

En Ecuador, el daño y la reparación han pasado de un esquema estrictamente civilista a ser regulado en la normativa constitucional del 2008, con acertadas disposiciones que constan en la legislación secundaria bajo la denominación de reparación integral. De esta forma, los jueces civiles y penales deberán velar por el cumplimiento de su función de garantes de los derechos constitucionales, y aminorar el padecimiento de la víctima o retornarla a su estado anterior.

Con la reparación integral, Ecuador asumió así su compromiso y respeto a los derechos humanos, incluyendo este nuevo mecanismo de justicia en todo ámbito.

\section{Referencias bibliográficas}

Abad, C. (2020). La dimensión de la reparación integral en la acción de protección. [Tesis de Maestría]. Universidad Andina Simón Bolívar. https://repositorio.uasb.edu.ec/bitstream/10644/7788/1/T3371-MDC-Abad-La\%20dimension.pdf

ALDEA / Asociación Latinoamericana para el Desarrollo Alternativo (2018). Un femicidio cada 3 días en el Ecuador. http://www.fundacionaldea.org/noticias-aldea/ c6cwr7g9cs6klz56rkksktalk756t4 
Ariadna, I. (2021). Sociología de la familia. Economipedia.com

Asamblea Naciones Unidas (1993). Día Internacional de las Familias, 15 de mayo. Recuperado el 09 de julio de 2018. http://www.un.org/es/ events/familyday/

Bentivegna, S. (2016). La gran telaraña. Ed MEGUSTAESCRIBIR. E book Buenos Aires. Bofarull, I. (2005). Ocio y tiempo libre: un reto para la familia. Colección Astrolabio. Familia. Cabella, W. \& Nathan, M. (2018). Los desafíos de la baja fecundidad en América Latina y el Caribe. Fondo de Población de las Naciones Unidas (UNFPA). https://lac.unfpa. org/sites/default/files/pub-pdf/Baja\%20fecundidad\%20en\%20ALC\%20-\%20version\%20web\%20espa\%C3\%B1ol.pdf

Canseco, E., Rivera, M., \& Álvarez, C. (2019). Prevención de las formas de violencia intrafamiliar, causas y consecuencias en los habitantes del sector Miramar de Manta, Ecuador. Revista Científica y Arbitrada de Ciencias Sociales y Trabajo Social: Tejedora. 2(3), pp. 2-11. https://publicacionescd.uleam.edu.ec/index.php/tejedora/article/ view/29

Cornejo, J. (2016). La Reparación Integral. https://derechoecuador.com/la-reparacionintegral/

Díaz, T. et all. (2004). La familia cubana: realidades y proyección social. Revista Temas. 36.

Escudero, J. (2013). Reconocimiento Constitucional del Derecho a la Reparación Integral y su Complicado Desarrollo en el Ecuador. Quito: Corte Constitucional del Ecuador.

Espinoza, B. (2021). 105 feminicidios se registraron en todo el Ecuador solo en seis meses; una mujer es asesinada cada 41 horas. Radio pichincha FM. https://www.pichinchacomunicaciones.com.ec/105-feminicidios-se-registraron-en-todo-el-ecuadorsolo-en-seis-meses-una-mujer-es-asesinada-cada-41-horas/

Gil, M. (2019). El origen del sistema patriarcal y la construcción de las relaciones de género. AGORARSC. https://www.agorarsc.org/el-origen-del-sistema-patriarcal-y-la-construccion-de-las-relaciones-de-genero/

Gorski, A. (2017). "El Ciclo de la Violencia": cuáles son sus etapas y cómo ponerle fin. Infobae. https://www.infobae.com/tendencias/2017/05/04/el-ciclo-de-la-violenciacuales-son-sus-etapas-y-como-ponerle-fin/

Illescas, M; Tapia, J \& Flores, E (2018). Factores socioculturales que influyen en mujeres víctimas de violencia intrafamiliar. Revista Killkana Sociales, vol. 2, No. 3, pp. 187 196. https://doi.org/10.26871/killkana social.v2i3.348

Machado, L., et al. (2018). Reparación integral en el sistema jurídico ecuatoriano; ¿¿derecho público o privado?. Espacios vol. 39, N. 9, p. 14.

Madrid, M. \& Reyes, J. (2019). Efectos en la dinámica familiar producto de la formación y experiencia laboral de los colaboradores del servicio de protección institucional y su propuesta de atención 2019. [Tesis Maestría En Política, Promoción E Intervención Familiar.] Universidad de Panamá. http://up-rid.up.ac.pa/3408/1/ maria_madrid.pdf

Mayor, S. \& Salazar, C. (2019). La violencia intrafamiliar. Un problema de salud actual. Gaceta Médica Espirituana, 21(1), pp. 96-105. http://scielo.sld.cu/scielo. php?script=sci $\_$arttext $\&$ pid $=S 1608-89212019000100096 \& \operatorname{lng}=$ es \& 2 lng $=$ es

Ministerio de Justicia, Derechos Humanos y Cultos (2014). Código Orgánico Integral Penal (COIP). Gráficas Ayerve C. A. Quito.

Ministerio de Relaciones Exteriores y Movilidad Humana (2018). Política para la igualdad de género. https://www.cancilleria.gob.ec/wp-content/uploads/2018/02/politica para la igualdad de genero 2018.pdf 
Morgan, H. (1971). La sociedad primitiva. Madrid: Universidad Complutense.

Oudhof, H. Mercado, A., \& Robles, E. (2019). Cultura, diversidad familiar y su efecto en la crianza de los hijos Estudios sobre las Culturas Contemporáneas. Universidad de Colima, vol. XIV, N. 48, pp. 65-84.

Pliego, F (2014). Las familias en México. Editorial Porrúa. DF México.

Reuben, S. (2003). El Carácter histórico de la familia y las transformaciones sociales contemporáneas. Reflexiones. No 80(2).

Saccomano, C. (2017). El femicidio en America latina: ¿vacío legal o déficit del Estado de derecho? Revista CIDOB d'Afers Internacionals 117, pp. 51-78, 62.

Torres, A. (2019). Causas y consecuencias de la violencia intrafamiliar en mujeres y nińos pacientes del Centro de Salud tipo C de Catamayo Provincia de Loja en el periodo enero- julio 2015 y la intervención del trabajador social. [Tesis de grado Trabajo Social]. Universidad de Loja.

\section{Legislación}

Código Orgánico Integral Penal. Registro Oficial N. 180 de 10 de febrero de 2014.

Constitución de la República del Ecuador. Registro Oficial N. 449. 20 de octubre de 2008.

Ley para Prevenir y Erradicar la Violencia contra las Mujeres. Registro Oficial N. 175 de 05 de febrero de 2018.

Ley Orgánica de Garantías Jurisdiccionales y Control Constitucional. Registro Oficial N. 52 de 22 de octubre de 2009.

\section{Sentencias y Resoluciones}

Corte Interamericana de Derechos Humanos (2006). Caso Acevedo Jaramillo y otros Vs. Perú. Sentencia de 24 de noviembre de 2006.

Convenciones, Tratados y Conferencias

OEA / Organización de los Estados Americanos. (1994). Convención Interamericana para Prevenir, Sancionar y Erradicar la Violencia contra la Mujer (Convención de Belém do Pará).

ONU / Organización de Naciones Unidas (1948). Declaración Universal de los Derechos Humanos. Washington, Estados Unidos: ONU. 10 de diciembre de 1948. 